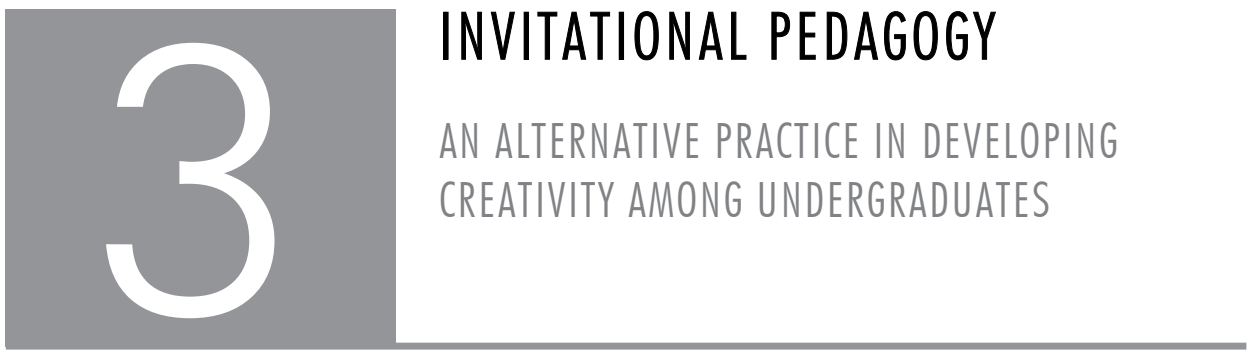

Teboho Pitso

\title{
INTRODUCTION
}

Higher education in the 21 st Century is increasingly coming under intense scrutiny and pressure to provide education that is more focused on resolving real-life societal problems, which often suggests learning that is less abstract, less distant from real-life issues and less discipline-bound. The spotlight of this public scrutiny on higher education has tended to fall on teaching and research. Teaching and research are now expected to be organised in such a way as to make a positive contribution towards preparing graduates that can address seemingly intractable work-related and societal challenges (Brew 2003; Griffiths 2004; Wilcoxson, Manning, Johnston \& Gething 2011). An educational endeavour of this nature often calls for the transcending of disciplinary boundaries and the elimination of the artificial binary between teaching and research. It is important to note that, historically, the relationship between teaching and research has largely proceeded on the basis of the post-epistemic condition. The post-epistemic condition refers to the separation of teaching from research and content-loaded curriculum where textbooks are the primary means of informing students about the outside world in a manner that is "distant and distancing" (Kalantzis \& Cope 2008:195). This condition impacts on how pedagogy is organised and practised especially, in undergraduate studies, which mostly exclude inquiry-based learning.

Based on this call to implicate higher education in societal challenges, a research project was set-up within undergraduate studies at a University of Technology in South Africa. This research project attempted to provide extended opportunities for undergraduate students to search and contribute creative technical solutions to environmental challenges. The focus of this project was, therefore, on giving final-year undergraduates opportunities to search for the near-optimal conditions of existing water distribution, paper and energy production technologies. 


\section{THE SCHOLARSHIP OF TEACHING AND LEARNING IN HIGHER EDUCATION}

My quest in the study was to offer senior undergraduates the chance to deal with real-life issues and the opportunity to synthesise the knowledge and experience they gained during the undergraduate years to solve real problems. In embarking on this project, I, an academic developer, with full participation of the teacher of the respective undergraduate class, was fully aware of the challenges that faced the successful launching of the project. First, these students were expected to shift away from learning environments where they have become used to answering questions preset for them, solve problems identified and defined for them by teachers or textbooks, and towards dealing with case studies that contained vaguely defined problems and where solutions were not straightforward. More importantly, students were made aware that we and many other people in society worldwide were still grappling with these problems so that we also had no immediate answers to the problems in the case studies. Second, for students used to answering and not posing questions, the thought of venturing into this virgin territory was likely to be insurmountable. There was a need to find an enabling pedagogy - one that was fundamentally different and that held better prospects of developing learning environments where students could feel safe to try out new things, fail, and try again without the guilt often associated with failure.

The main aim in this project was to develop students with creative dispositions and the project was informed, mainly, by the assumptions that the 21 st century job designs are increasingly dealing with novel challenges and the synthesis of the big picture scenarios (Cunningham 2006; Florida 2002; Pink 2005). Furthermore, creativity is seen as the basis of providing students with the capabilities that help them take a fuller and more productive role in the knowledge-driven society (Castells, Muller, Cloete \& Badat 2001; Florida \& Goodnight 2005; Peters 2003). There was also commitment not only to developing inquiry-based learning opportunities in the project but also to systematically investigating the effectiveness of the learning conditions that were attempted in the project, which were enacted in the form of "learnshops", involving "invitational pedagogy", both of which will be elaborated on later in the chapter. There was a genuine attempt, in setting up this project, to breach the gap between research and learning through inquiry-based learning. A similar effort was made to close the gap between research and teaching in line with Boyer (1990) and his call that teaching should be accepted as an integral part of scholarship.

However, Boyer's call was not only for teaching to be designated as the object of inquiry where the systematic study of teaching was intended to understand how teaching could improve students' learning. Boyer's other position, which receives little attention in literature, was also on calling for change in undergraduate education to 
cater for inquiry-based learning (Boyer 1998). However, inquiry-based learning, of itself, does not constitute scholarship as it has to meet the condition that such efforts should have to be systematically studied and possibly refined as well as be publicly shared and critiqued.

Two versions of the Scholarship of Teaching and Learning are noted here. First, SoTL can be constituted for purposes of systematically understanding teaching and learning practices with the aim of eventually improving students' learning. Second, SoTL can be organised in such a way as to allow for teaching to be reconstituted relationally with learning in order to achieve different learning goals, in this case, developing students' creativity. In this way, SoTL is noted for its transformative nature of the relationship between teaching and learning with emphasis now placed on learning that has a strong inquiry orientation and which also situates students in real societal problems with teaching serving an ancillary role. In this chapter SoTL is viewed as:

The systematic study of teaching and learning, using validated criteria of scholarship, to understand how teaching (beliefs, behaviours, attitudes, and values) can maximise learning, and/or develop a more accurate understanding of learning, resulting in products that are publicly shared for critique and use by an appropriate community.

(Potter \& Kustra 2011:2)

My view of SoTL, largely resonating with Potter and Kustra (201 1), is, first, that efforts to investigate teaching and learning need to lead to some educational artefacts that can be shared among the community of scholars. It is, therefore, important to note that notions of private and undocumented reflections or informal sharing with colleagues of one's teaching and learning practices do not meet the criteria of SoTL as defined in this chapter.

Second, if the intended activities of systematically investigating teaching and learning do not lead to significant and almost direct benefits to students' learning and development, thereby closing the transactional space between teaching and learning, then practices of SoTL are not, I argue, worthwhile.

Third, SoTL efforts that do not meaningfully contribute towards the overhaul of university teaching, learning and research have to be put to rigorous scrutiny mainly because the traditional liberal values of the university as the place for cultural reproduction has to be challenged in this century. Kindeberg (this book) makes the point that education, in its conceptual essence, is a participatory activity which must be viewed as creative and transformative so that the knowledge base that we are attempting to develop in SoTL has, to a larger degree, led to constant innovative practices and reciprocity. Teachers and communities of scholars need to benefit from the results 


\section{THE SCHOLARSHIP OF TEACHING AND LEARNING IN HIGHER EDUCATION}

of students' research projects, developed on the basis of established and emerging knowledge. The gap between teaching and research as well as learning and research has to be significantly closed and SoTL has the opportunity to meaningfully contribute to that end. Teachers who choose and experiment on innovative practices of teaching and learning, such as use of case studies, and problem-based and inquiry-oriented learning, are seen as creative and transformative and therein lies the problem. If education is creative and transformative, as Kindeberg suggests, then teachers who employ traditional modes of teaching and learning need to be seen as oddities, rather than those who are creative and committed to constant positive change of teaching and learning to better maximise students' learning and development. Creative teachers recognise that teaching is but one of many ways students' learning takes place and provide learning opportunities beyond the classroom (Bowden \& Marton 1998).

The study reported in this chapter was conceptualised in such a way as to illuminate the transformative potential of SoTL. This was done through the study and reconstitution of an existing pedagogy by means of emphasising an alternative dialogic arrangement, reorganising the transitions that needed to take place and expanding knowledge sites to non-traditional sites for knowledge appropriation. This massive educational effort was attempted through combining the theories of rhetoric, knowledge, teaching practice and learning. This innovative pedagogy sought to engender questioning attitudes in students, promote their research project designs and foster an increased awareness of how they can productively interact with others in searching for novel solutions to real-life issues.

\section{THE IMPACT OF TRADITIONAL LEARNING ENVIRONMENTS ON DEVELOPING STUDENTS' CREATIVITY}

Research on developing students' creativity in higher education over the last few years has first, been focusing on capturing meaning variations on how teachers and students understand creativity (Edwards, McGoldrick \& Oliver 2006; Jackson 2008; Jackson \& Shaw 2006; Pitso 2011). Second, such research has been paying attention to how traditional teaching practices, especially at undergraduate level, have been deliberately marginalising creativity while considering it, at a rhetorical level, as an equally legitimate goal of undergraduate education (Boyer 1998; Dillon 2006; Törnkvist 1998). Third, research on developing students' creativity has tended to focus on how learning environments can be better organised to promote the development of students' creativity (Baillie \& Walker 1998; Cropley 2000; Forrester \& Hui 2007). 
In each of these investigations on understanding and developing creativity within the strictures of undergraduate curricula and pedagogies there is the general consensus that traditional learning environments are mostly inimical and incapable of cultivating high-order thinking skills such as creativity. In attempting to capture the meaning and variations of creativity among the higher education classroom actors, creativity scholars were making an effort to deal with two critical issues related to creativity and higher education. First, they were dealing with the reality that creativity is a contested and highly contestable concept which complicates things for higher education institutions as most are oriented towards delivering past knowledge in the mode of transmission and pre-set questions with definite answers (Csikszentmihalyi 2006). Second, creativity in higher education has to be understood within the framework of complex learning with entrenched critical and rational thinking (analytical and reasoning processes). Creativity scholars that focused on synthesising higher education classroom actors' ideas around creativity also dealt with the issue of finding out whether space and time could be allocated to the development of students' creativity.

For instance, the qualitative study of Oliver, Shah, McGoldrick and Edwards (2006) on higher education students' conceptions and experiences of creativity show that students experience notions of being academic and being creative as conflictual as the former inclines towards controlling, conforming and producing clones while the latter supports the development of new ideas. In both these instances, these students believe that different sets of learning tools are required, with rote learning, restrictive one-definite-answer based methods and regurgitation strongly associated with being academic.

Another issue receiving little attention in these works is the ways in which creativity is understood in classroom contexts in higher education, and the extent to which these variations in meaning of creativity reveal the likely reaction of classroom actors to the idea of developing creativity in their classrooms. In my own study, I found that classroom actors who have elaborate meanings of creativity tend to be in favour of finding space and time for the development of creativity, while those who show restricted conceptions of creativity do not (Pitso 2011). This issue was particularly relevant in shaping and guiding my design of an alternative pedagogy, as elaborated later in this chapter.

In more recent times, the overly "academic" undergraduate studies have increasingly come into the spotlight for their general marginalisation of creativity and lack of an inquiry orientation. Törnkvist (1998) suggests that the hybridisation of three educational approaches has been instrumental in the general marginalisation of 


\section{THE SCHOLARSHIP OF TEACHING AND LEARNING IN HIGHER EDUCATION}

creativity in undergraduate studies. First, undergraduate education is generally based on established and settled knowledge that had been generated in such a way as to have universal appeal and applicability. It is this underpinning of undergraduate education on clean, universal knowledge that has, according to Törnkvist (1998), entrenched pedagogies that transmit past knowledge to students. This, in turn, compromises focus on real-life present and future scenarios which may require more than just the guidance of settled knowledge. Given the dualistic nature of this knowledge (Cohen, Manion \& Morrison 2000) there has been the tendency to prepare especially undergraduate students to answer pre-set questions with definite answers rather than orientating them to ask deep, complex questions with no readymade solutions.

This point leads to the second issue that Törnkvist (1998) raises, which is that undergraduate studies are noted mostly for the drill and practice routines which can hardly assist students to think creatively. Chang and Hsiau succinctly capture this view of undergraduate classrooms as:

Indoctrination of domain knowledge [...] most problems given to students in class are well defined with only one correct solution. Under current training, students are asked to solve these 'textbook' problems, which are simple, well formulated in particular forms, and have standardised approaches and answers.

(Chang \& Hsiau 2002:64)

Törnkvist (1998) further argues that undergraduate education has relied heavily on abstract mental schemas as the basis of learning and making sense of experience at the expense of developing concrete context-based, situated schemas. I believe both sets of mental schemas have a place in the fostering of students' creativity. Ideas generation, hypothesising and synthesising are as equally valid as practically applying solutions to almost intractable real-life problems.

Another critical factor that is considered relevant in the general marginalisation of creativity especially at undergraduate level is the module-based semester system, which drives the content-loaded undergraduate curricula (Edwards, McGoldrick \& Oliver 2006). The implication of this approach to undergraduate education is that it tends to pressure teachers into completing the prescribed syllabus. This approach thus allows very little space and time for formative approaches to pedagogy where reflective practice and iterative improvement of one's practice are made possible. According to Runté, teachers operating under these industry images of division of labour, task management and strict timeline: 
Feel pressured to teach to the test, rather than to respond to student interests [...] teachers retreat into rote memorisation of the basics, rather than encouraging critical thinking (and creative thinking), because they know that most standardised examinations are incapable of measuring such higher mental activity.

(Runté 1995:14)

\section{DEVELOPING INVITATIONAL PEDAGOGY}

The challenge facing undergraduate education is its orientation towards the knowledge of the past (settled and unproblematic) and its narrow focus on developing students that are competent on this past knowledge. These students rarely show abilities of coping and dealing with emerging and uncertain knowledge. According to Csikszentmihalyi (2006), young people today face situations that differ materially from situations of the past for which knowledge was generated so that "the past is no longer as good a guide to the future as it once had been" (p.xix). Csikszentmihalyi (2006) also suggests that, as the results of this backward-looking approach to education, pedagogies that have proved effective are those that focused on developing learning environments that concern themselves with transmission of established knowledge.

In the study that is reported in this chapter it was particularly important that students should be able to relate and, where needs be, apply these past ways of knowing to grapple with complexity and uncertainty embedded in the case study problems. The purpose was mainly to expose the limits of this generally fragmented past knowledge and open-up spaces for its combination with emergent knowledge to solve real-life problems encapsulated in the case studies. It was also important to lay bare the limits of learning disciplinary knowledge as isolated pieces of knowledge by exposing students to real-life problems. Case studies provided students with opportunities to engage non-routine problems with non-obvious solutions. Even more challenging was that the case studies involved engaging students in efforts of clearly delineating the problem because this was also not made obvious. This approach to problem solving had a very strong inquiry orientation and while students were expected to initially focus on the past knowledge that resulted in the design of the technology, this occurred within the framework of problematising, critiquing and improving on this knowledge. The implied students' transition was on moving from the culture of rote learning, acquirers of received knowledge and dualist modes of knowing, towards levels where they could analyse, evaluate, hypothesise, synthesise, critically reflect and generate novel ideas as they search for the ideality of chosen technology. 


\section{THE SCHOLARSHIP OF TEACHING AND LEARNING IN HIGHER EDUCATION}

It also became increasingly clear to the students that they may need to conduct offcampus visits to better inform themselves of their chosen technology if they stood any chance of contributing towards its ideality. Given this mammoth paradigmatic shift in learning and the high risks of the consequent learning anxiety paralysing students into inaction, it was particularly important that an alternative and enabling pedagogy was designed. The challenge in the design of the alternative pedagogy was on the kinds of dialogues that needed to be constructed and the degree of agentic and discretionary powers that could be allowed to students without creating laissez faire learning environments. The threat that creativity development initiatives can be reduced to ridiculous levels exists and had to be carefully considered in the design of the alternative pedagogy. It was also important to ground the design of the pedagogy on solid knowledge base and its testing on reliable empirical data.

Of note is that two undergraduate classes were invited to participate in the study and the one that remained in the project was from the teacher who provided more elaborate meanings of creativity during an interview prior to the start of the project. This issue is particularly important because it suggests the need to choose teachers who can help champion the cause of creativity, especially when it is introduced in areas or domains were buy-in is still necessary. That the teacher could provide some elaborate meanings of creativity suggests some interest in creativity, hence the effort that might have been invested in understanding creativity.

In designing the pedagogy, the focus went first to dialogue. Dialogues are central in oral interactions, which Kindeberg (this book) describes in some greater detail. One key issue that Kindeberg brings out is the need to mediate and mitigate power between the teacher and students. Tom (1997) suggests that teachers should acknowledge that such power imbalance exists so that they could successfully confront it. Dialogues have a long history that can be traced from rhetoric - the study and science of communication.

In my own study I found that the positioning of students on established knowledge (unknown to students but well-known in the discipline) affected the pedagogic conditions in the classroom. First, it created routines where the teacher was overly active and students were overly passive during the knowledge transfer encounters which assumed a largely linear approach (shifting students from the unknown to the known state). Second, the power imbalance between the teacher and students was mediated through transactions of classroom agency and discretion which largely, the interviews data revealed, favoured the teacher. Upon requesting the teacher who participated in the project to describe his most consistent teaching actions, the teacher had this to say: 
Introducing the topic and find out whether the students have knowledge about the related topic by asking them questions, then explain the content of the topic, then we do the example (calculations) and they have to solve the problems.

(Pitso 2011:141)

In this description of the teacher's teaching actions, it is not unreasonable to suggest that relations of authority and conduct were immediately clear to students and the rules of legitimate expectations in terms of students' conduct, what needed to be learned and how that should proceed were quite palpable. The temporal demarcations of knowledge were implicitly expressed by the teacher. I gained little sense that students could have opportunities or even that opportunities could be created for them to pose deep, complex questions under these pedagogic conditions. The oral interactions, it can reasonably be inferred, were highly regulated and controlled. The students' interviews data corroborate the teacher's written descriptions of his consistent teaching actions: "Most of the time I first think or understand the promblem [sic] and check what I have, from there I check the method to be used and I solve the problem" (Pitso 2011:144).

In attempting to make sense of these pedagogic conditions in respect of oral interactions and in an effort to search for the way forward for the project I referred to the work of Foss (1993) on rhetoric. My sense-making of the oral interactions that were to occur in the project was informed mainly by the realisation that students needed to be given opportunities in the learnshops to draw from the knowledge, skills and experiences they have developed both informally and formally.

The main purpose, as suggested earlier, was to expose the limits of their current knowledge, skills and experiences but, more importantly, to bring them into a new awareness that more knowledge, more skills and new experiences were going to be vital if they were to, marginally, succeed in resolving the problems in the case studies. In this sense, the focus of oral interaction was going to mainly be among the students themselves so that, in the learnshops, the power distribution (and possible imbalance) was going to take place among the students. Oral interaction and its concomitant issues of power was still a matter to be investigated thoroughly and mitigated in the project and the work of Foss (1993) on invitational rhetoric formed the basis of the investigation. It is important to note that oral interactions can be constructed as monologues or dialogues.

For the purpose of this study, oral interactions are considered as constructed dialogically because the assumption is that the pedagogic situation is almost impossible to construct monologically because the role of the students even in situations of strict 


\section{THE SCHOLARSHIP OF TEACHING AND LEARNING IN HIGHER EDUCATION}

control and regulation is still vital and necessary. According to Bakhtin and Holquist (1981), dialogic constructions are noted for double-voicing, which he defines as the suggestion that whoever speaks must be aware of the right of the listener(s) in the utterance and enter into a dialogic engagement with it. This view of dialogues was particularly important in the alternative pedagogy I was developing. First, there was a need to elevate students from the position of being the object of pedagogical influence to the status of being active and creative participants that had the power to shape and influence the pedagogic conditions. I had to construct the pedagogic conditions in such a way as to constitute an invitation to students to try out new things in the safe and secure space of the pedagogy. Second, I had to smooth out power imbalances among the students themselves as they functioned in a group context so that it was the students, unlike in Tom's study, which focused on the power imbalance between teachers and students who had to confront and challenge their senses of superiority and inferiority in the problem-solving encounters. I was guided, in my efforts to create safe conversational spaces, by the theory of invitational rhetoric. It posits the view that dialogues that hold better prospects of facilitating collaborative processes need to go beyond persuasion and allow participants the opportunity to self-persuade based on the evidence and discussions that ensue in the dialogic engagement (Foss 1993).

The basis of developing the alternative pedagogy was mainly to restore students' agentic and discretionary power through creating learning environments where students could engage in independent research. Invitational dialogic constructions were central in these efforts. It is not unusual for undergraduate students to engage in research and function under invitational pedagogic conditions. While not widely covered in education, the development of the physics canon in the middle of the 18th century in Germany involved students' experiments and students' presentation of their results to the physics community. The German physicist, Wilhelm Weber (1804-1891) became one of the first scientists and teachers to encourage students' active participation in physics through conducting experiments and sharing their findings in the classroom (Olesko 2005). This Weberian approach to pedagogy is completely different from the practice of letting students conduct experiments in the laboratory to confirm what the lecturer already knows or what is already confirmed as a fact in the textbook, amounting to replication of those experiments.

The outstanding features of Weber's innovative pedagogy were his focus, jointly with his students, on testing the reliability and sensitivity of a physics instrument, his concentration on the methods for measuring Earth's magnetism and his reliance on advanced students of physics to handle introductory students' learning 
(Olesko 2005). Weber is also attributed with attempts to develop a more inclusive approach to learning physics that sought to accommodate students from all levels and from a variety of disciplines. By 1850, Weber was relying on peer mediation to pursue conceptual understanding of terrestrial magnetic measurements while he focused on the practical exercises on bifilar systems, the determination of the moment of inertia of a vibrating magnetic bar, theories of instruments and measuring absolute intensity and magnetic inclination and declination (Olesko 2005). Weberian innovative pedagogy also ensured that those advanced students involved in peer mediation were being prepared to conduct independent research projects. The pedagogic innovation, however, while laudable for allowing students some space for active participation and room for decision making, was tainted by his insistence on research mentoring based on subordination and hierarchical delegation of authority.

It was further undermined by his belief on innate inclination and talent as determinants of students' science propensity (Olesko 2005:327-328). Weberian pedagogy also introduced peer assessment as Weber encouraged students to evaluate each other's data and discuss results in the seminars and practicals (Cahan 1985).

However, it is Friedrich Kohlrausch (1840-1904), Weber's student and later his assistant at Gottingen Physical Institute, who took innovative pedagogy to another level, where issues of power were significantly reduced and collaboration between himself and the students and among students themselves was accentuated (Olesko 2005). Kohlrausch's approach to pedagogy is recognised largely because it inculcated social norms, which science and physics tended to downplay. It is Kohlrausch who empowered students through making them partners in research and establishing guidelines for interacting with experienced and supporting members of the community. He created the means through which students took part in their own learning and in educating others. The relationship between Kohlrausch and his students and among themselves was characterised by receptivity to criticism and a cooperative spirit (Olesko 2005:328). Students, learning under this pedagogy, also learned to respect one another through including student-driven innovations in practical exercises. Of particular significance is the fact that the roles and responsibilities of the teacher and student were shared as the presentations rotated among them (Olesko 2005). Under these pedagogic circumstances, the line between teaching and learning blurred as students learned to present themselves and their topics as if they were "professionals". In these presentations, advanced students participated not only as transmitters of knowledge but also in the creation and organisation of knowledge. Kohlrauschian innovative pedagogy's greatest contribution to pedagogy is the role it accorded both the teacher and the advanced students as partners in research so that 


\section{THE SCHOLARSHIP OF TEACHING AND LEARNING IN HIGHER EDUCATION}

there was a temporary fusion of their identities as researchers (Olesko 2005). The environment under which this pedagogy throve was invitational rather than conquest or conversion-based both of which have the intention to change others' position on a matter. It is Kohlrauschian innovative pedagogy that was attempted in learnshops to provide opportunities for students to learn in a research and collaborative mode.

\section{IMPLEMENTING AND TESTING INVITATIONAL PEDAGOGY IN LEARNSHOPS}

In what I am terming a learnshop, a play on learning and workshop, conditions were created where students were given opportunities to solve real, practical problems that seasoned experts were still grappling with rather than working within the framework of "expert solved problems", as guided by invitational rhetoric and an inquiry orientation. Students were given time and space in the learnshops to attempt real solutions to real problems, which included searching for relevant information even outside academia. It was also expected that students would transit from dualistic ways of seeing things as right or wrong towards the recognition that areas of legitimate uncertainty and diversity of ideas exist (Perry 1970).

\section{Learnshops 1 and 2: Setting the scene for invitational pedagogy}

Informed by the study of Martinsen (1995), which suggests that replication-oriented students, such as those mostly in undergraduate studies, perform better in creativity activities when there is a high level of experience condition, I opted for guided creative problem solving. This means that students need a certain level of tutelage (process and people) when exposed to learning conditions where they must seek new types of solutions and new ways of solving problems. Based on this underpinning, I arranged that the first two learnshop sessions should serve to prepare students for independent research and inquiry-based learning. I began by training them on the TRIZ-based Creativity Model (Figure 3.1, explained in greater detail later) and sharing my own understanding of sustainable development. I defined 'sustainable development' as the ability of the current generation of human beings to meet its present needs through prudent use of natural resources without risking the ability of future generations to meet their own. I also briefly explained the model as I also demonstrated how the simplicity of the model served to provide support to students to build confidence and the self-belief that they could successfully engage in creative problem solving. The first two sessions were also used to divide students into three teams of six members each and to give each team the opportunity to choose their own case study. Students' existing creative abilities were also pre-tested through the standardised Torrance's Tests of Creative Thinking (TTCT), which measured students on three metric variables 
of fluency, flexibility and originality. Fluency refers to the number of ideas each person generates, flexibility measures the variety of those generated ideas and originality calibrates the unusualness of the ideas.

Students were trained on how to create safe conversational spaces, which are vital in safeguarding the invitational nature of the learnshops, through identifying key destroyers of the free flow of dialogic engagements. There are, at least, two types of those destroyers of safe conversations. First, people in conversations are more likely to withdraw, mask or avoid the conversations when they feel threatened and thus employ the strategy of silence, which involves withholding information from the team. Conversational withdrawal means that the person exits the conversation; masking involves using sarcasm or other communication ploys that help the person to understate his or her contribution; and avoidance refers to withdrawing from uncomfortable topics. Second, people in conversations may attempt to launch a verbal attack, use 'grotesque' labels or attempt to control the conversations as strategies to compel people to accept their points of view, however weak they might be. This is what Foss calls 'conquest rhetoric' where the speaker makes every attempt to win over the audience to his or her point of view (Foss 1993). Verbal attacks may include the use of threats and insults to attempt to win over people to one's point of view. Labels may include placing the ideas or points of view of others under offensive categories with the purpose of undermining or dismissing them, while controlling involves speaking in absolute or exaggerated ways as ways of winning people over to one's point of view. It was my view that by constantly patrolling conversations and being constantly alert to these conversation killers, students would be able to identify and marshal against these conversational safety violations and thus constantly guard their dialogues against these dangers.

The Creativity Model (Figure 3.1), on the other hand, involves six steps that were derived from the TRIZ theory. TRIZ is derived from the Russian phrase "Teoriya Resheniya Izobretatelskikh Zadatch" which translates into "The theory of inventive problem-solving" (Rantanen \& Domb 2002:1). TRIZ is a heuristic problem-solving theory developed by the Russian Genrich Saulovich Altshuller in 1946. By the late fifties it had become a powerful methodology for creative problem solving in engineering (Savransky 2000). The uniqueness of TRIZ resides in:

[T] he use of a relatively small number of concepts, heuristics and effective knowledge databases to solve non-routine problems of any of the classes of problems ranging from the improvement of quality or/and quantity to the search for and prevention of shortcomings through creation of fundamentally new techniques to fit new needs.

(Savransky 2000:ii) 


\section{THE SCHOLARSHIP OF TEACHING AND LEARNING IN HIGHER EDUCATION}

TRIZ is also a model-based technology for generating novel ideas and solutions, and thus it becomes compatible with any type of creativity that searches for ideality of existing technologies. TRIZ, unlike other problem-solving techniques such as brainstorming, which derives from random ideas generation, aims for systematic and scientific approach to the invention of new systems and the refinement of existing ones (Savransky 2000:4-7). TRIZ has proved to be effective in problem formulation, system analysis, system failure analysis and patterns of system evolution (Altshuller 1984; Polivinkin 1985, 1991; Sklobosvsky \& Sharipov 1995).

According to Rantanen and Domb (2002), TRIZ supports most of the features of good solutions because it ensures that contradictions in the system or technology are resolved through finding relevant information to eliminate these contradictions. TRIZ tends to focus on the use of idle resources thus pitching it closer to the sustainable development discourses with their emphasis on bridling the use of natural resources. TRIZ is also recognised for its reorganisation of creative activities. This allows for the transition from the existing ways of conventional problem solving where contradictions of the technologies or systems are hidden, thus leading potentially to the use of additional resources to new ways of systematic and creative problem solving where contradictions are clarified, idle resources are used and ideal outcomes are illuminated early on to guide the solution space.

The first critical step in the TRIZ-based Creativity Model relates to the thorough understanding of the technology at hand as a precondition for attempting its ideality. This is shown at Box 1 in Figure 3.1. As suggested by Savransky (2000), without such knowledge of the technology any attempt on its ideality may be significantly compromised. The underlying principle in this first step of the model is to demystify the technology and the science behind it.

Problem solvers need to have a thorough knowledge of the design and operations of the technology under investigation as well as the science and natural resources that were used in developing it. Without such understanding of the basic issues involved in the technology under investigation, problem solvers may find it extremely difficult to search for its near optimal status and the trade-offs that may have to be made in order to achieve the near-optimal conditions of the technology. Understanding the technology and the science that informs it is, therefore, a basic requirement in any attempt to search for its near optimal status. It is further expected that problem solvers would take seriously the global call for reducing greenhouse gas (GHG) concentrations and the unfettered use of natural resources and consider the use of eco-friendly resources as part of the search for the near-optimal operations of existing technologies which may be improved or retired to make space for new ones. 
Step 2 entails determining the current ideality status of the technology, putting questions that focus on whether the technology is operating at near-perfect levels. Given that almost all technologies designed during the industrial age were premised on unfettered use of natural resources (Castells, Muller, Cloete \& Badat 2001; Korten 1995; Suzuki 2009), it was taken for granted that most existing technologies would require rethinking and possible redesign to cater for the new dwindling status of natural resources. Focus in the second step is on the search for cheaper and more environmentally-friendly resources that are bio-degradable and emit less greenhouse gases (Susuki 2009). In the learnshops, I provided some evidence of the environmental challenges of the technologies related to water, coal-based energy and paper production. Students were expected to investigate the issues further.

The third step relates to the causes or constraints that prevent the technology from operating at near-perfect levels. It was expected that students would add to this list of possible causes or constraints as and when their own systematic investigation points to a different set of causation or constraints. It is important to note that this step entails all the six classes of inventive problem solving. These classes of inventive problem-solving are divided in terms of whether they require an entirely new solution or change in the existing techniques.

Class 1, improvement or perfection in both quality and quantity of product or service, focuses on reducing contradictions in an existing system or technique. The search for and prevention of shortcomings, Class 2, attempts to diagnose weaknesses, contradictions and flaws in a system or technique before they actually occur and moves towards proactiveness. Class 3, cost reduction of existing technique, attempts to trim or significantly reduce existing inputs (capital, human and physical resources) without compromising outputs (products or service). Its primary focus is on productivity of an entity. Class 4, new use of known processes and systems, is analogous to trying out new ways by sensing limits and creating new insights that transform existing processes and systems into more effective instruments. Class 5, generation of new "mixtures" or hybrids of already existing elements, synthesises these elements in ways that foreground new thinking, new insights and new ways of doing things. It was anticipated that students may identify factors that cause the problem within a particular technology and be able to relate them to any of the six classes of inventive problem solving or even add new factors or causes of the problem.

Step 4 involves decisions on the transition that may be chosen by students in an attempt to resolve identified causes or constraints which would compel them to decide on the pattern of evolution that may be required to achieve the higher design of the chosen technology, even at a level of gaining insight. For example, in order to 


\section{THE SCHOLARSHIP OF TEACHING AND LEARNING IN HIGHER EDUCATION}

solve the problem of having to wait for a person to complete talking on a telephone, the engineers who developed mobile phones opted for a pattern of evolution that involved shift from the macro-level (telephone) to the micro-level (mobile phones). The key principle that guided the solution was the principle of segmentation. It is important to note that steps four and five are closely related and operate at the level of the solution space.

In Step 5 the choice is on the principle that needs to guide the solution and is directly linked to Step 4. The final step, Step 6, involves identifying and estimating the resources that may be required in order to resolve the factors that cause the technology not to perform near-perfect. For instance, in the case of the mobile phones, the problem solvers had to balance the costs of producing the mobile phones and the need to make them more affordable so that both hardware and software costs had to be taken into account including the size and shape of the mobile phones.

\begin{tabular}{|l|}
\hline Conceptual Understanding \\
- Accurate explanation \\
- Think logically \\
- Accurrect application \\
- Multiple views \\
- Sense limits \\
\hline
\end{tabular}
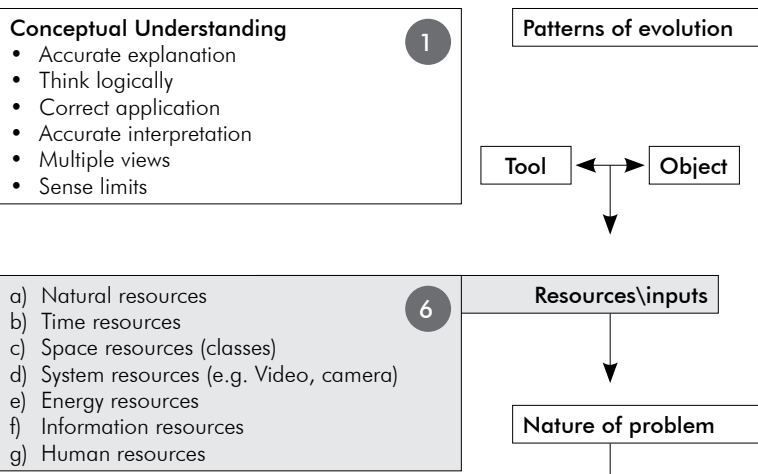

\section{Transitions}

i. To micro-level (segmentation)

ii. To macro-level (integration)

1) Contradiction: improves or perfects the system (quality, quantity)

2) Diagnosis: searches \& prevents short comings

3) Trimming: reduces costs of existing technique/strategy

4) Analogy: makes new use of known processes and systems

5) Synthesis: generates new combinations of already existing elements

6) Genesis: creates new technique strategy to fit new need

\begin{tabular}{|c|c|c|c|}
\hline Is the system working near perfect? & Outcome\idealisation & i. Segmentation & ix. Self-service \\
\hline $\begin{array}{l}\text { What does it mean when the system is working } \\
\text { near perfect? }\end{array}$ & $\nabla$ & $\begin{array}{l}\text { iii. Local quality } \\
\text { iv. Universality } \\
\text { v. Periodic action }\end{array}$ & $\begin{array}{l}\text { xi. Symmetry } \\
\text { xii. Clear focus } \\
\text { xiii. Merging }\end{array}$ \\
\hline [Outcome | Output] & Principles & $\begin{array}{l}\text { vi. Continuity of } \\
\text { useful action }\end{array}$ & $\begin{array}{l}\text { xiv. Backward } \\
\text { mapping }\end{array}$ \\
\hline & & $\begin{array}{l}\text { vii. Feedback } \\
\text { viii. Copying }\end{array}$ & $\begin{array}{ll}\text { xv. More } \\
\text { opportunities }\end{array}$ \\
\hline
\end{tabular}

FIGURE 3.1 The Creativity Model (Source: Pitso 2011)

\section{Learnshops 3 to 5: Inquiry mode and the creativity model}

Once students were advised on how to create safe conversational spaces, were orientated into the inquiry mode and received training on the creativity model, sessions 3 to 5 commenced. These sessions involved students' teams framing their problem-solving processes, which included the formulation of the problem and its 
clarification. We (I and the teacher) observed that students' teams struggled a lot with this aspect of the problem-solving process with team members holding divergent views on the nature of the problem and the appropriate question(s) to pose. Because this was the critical stage in the learnshops, we had to avoid the temptation to play a role in the teams' search for clarity of focus, as the clearly described problem help focus teams and directs further team actions. The general challenge that faced teams in these sessions was the correct description of the chosen technology and proper grounding on the knowledge base of the technology which teams could access through the internet search of relevant literature, other library searches and visits to actual sites where these technologies were operated. We had made internet, library and transport resources available for students' teams as long as each team was responsible for its own logistical plans. In this study, 'technology' is defined as any tool that is inserted between humans and nature to create some human convenience.

\section{Learnshops 6 to 8: The project outcomes}

During Learnshops 6 to 8, one team, the energy team, decided to organise a visit to Eskom-Lethabo, which is the largest South African energy utility company, to investigate the energy mix and renewable energy efforts of the company. The company is about $25 \mathrm{~km}$ from the institution. Prior to the visit, the energy team had to explain to all of us what is meant by energy mix and renewable energy, and why the team considered this as its focus. It was particularly important to determine whether the problem had significant reach, that is, whether it was worthy of investigation and the resources committed to it. The team explained 'energy mix' as the sourcing of energy from different natural resources through specialised technologies for human consumption with emphasis placed on shifting from coal-based energy generation towards renewable sources of energy, such as solar technologies, as ways of mitigating GHG concentrations. The team defined 'solar technologies' as the harnessing and conversion of radiant energy into chemical energy by using technologies that function in ways similar to the plant photosynthesis process. The team further provided statistics on the amount of solar energy that Earth's atmosphere, oceans and land masses absorb, which is estimated at 3850000 exajoules (EJ) per annum. This translates into so much energy per year as the world could ever obtain from all the earth's non-renewable resources such as coal, oil, natural gases and mined uranium combined. The team also provided information on the different types of solar technologies - active and passive. The 'active' solar techniques, according to the team, use photovoltaic panels, pumps and fans to convert sunlight into useful outputs, while the 'passive' solar techniques include selecting materials with favourable thermal properties, designing spaces that naturally circulate air and referencing the position of a building to the Sun. 


\section{THE SCHOLARSHIP OF TEACHING AND LEARNING IN HIGHER EDUCATION}

There was a general consensus that the team has shown, during its presentation on energy mix, grounded understanding of the issues involved in energy mix to proceed with its visit to Eskom. Upon return from the visit, the team had shifted focus away from energy mix discourses towards energy efficiency. According to the team, the interviews with Eskom personnel indicated that Eskom was not ready to fully migrate to renewable energy and thus the Eskom focus was on eliminating energy waste, which Eskom was unable to quantify at the time of the team's visit. The team then participated in the Eskom project of installing energy-efficient bulbs. This was presented in Learnshop 6.

When pushed on the merit of this exercise in terms of energy savings and how these savings could be quantified to justify their contribution in reducing GHG concentrations, the team was unable to provide quantifiable justification of these efforts. When using the framework of the Creativity Model to analyse how the team approached its creative problem solving, it is apparent that the team had a clear conceptual understanding of one aspect of the energy technology and that the team correctly identified the limitations of the current energy mix as an aspect of the energy technology that over-relies on a non-renewable resource of coal. It is also palpable that the original focus of the team was on identifying contradictions in the energy technology, which the team identified as over-reliance on coal-based energy generation and under-use of renewable energy sources to harness solar energy into utilisable energy. However, the focus of the team changed to trimming, which deals mainly with reducing the costs of operating the existing coal-based technologies by elimination of waste. Given this focus on costs reduction strategies, the team's solution could not involve any transitions which have become necessary in light of the postanthropocentric perspective on the use of natural resources which problematises the industrial age unfettered use of these dwindling natural resources. The transition is supposed to proceed from the macro-level of energy generation (centred on Eskom as the main national energy generator) towards the micro-level energy generation through household solar technologies or other alternative renewable energy sources where self-service could have led to better management of energy than periodic activities of energy saving efforts.

Another team examined the paper technologies used the institution as the unit of analysis and focused on the migration of the institution from paper-based information sharing, ranging from textbooks, study guides, communiqués and new and existing applications procedures, towards using electronic means. The team also focused on recycling of paper. The team's strategy was to establish direct link with the Mondi Recycling Unit so that waste paper within the institution could end up within this unit. When questioned on this approach, the team indicated that advances in digital 
media are such that paper-based technologies are becoming obsolete and that the focus should rather go towards mitigating current reliance on paper as society transits toward digitised information sharing.

After visiting Mondi (one of the largest companies that produce paper in the country), the team also described how the production of paper occurs, which showed the team's conceptual understanding of the technology. However, and given that the team wanted the transition towards digitised modes of information sharing, the paper production means were considered as problematic in this age and thus its focus was on generating new combinations of existing media of communication (paper and digital devices). The team's approach was on improving local quality of communication and information sharing with clear focus on complete transition to digital communication. The team's report was presented in Learnshop 7.

The team that investigated the water distribution technologies began its investigation through analysing the monthly consumption of water in the students' residences. The team analysed the monthly water bills by focusing on two different timeframes in the activities of the students' residences. The first timeframe was when the students were at the residences during the academic year and the other timeframe was when the students were mostly not at the residences during academic recesses. The team found that during the period when students occupied the residences the water bill was far less than when students were mostly not occupying the residences. This meant that during periods of less water consumption the water bill increased substantially and during periods of high water consumption the bill decreased substantially. This anomaly compelled the team to organise a field trip to Rand Water Board (the major distributor of water in the country) which is about $10 \mathrm{~km}$ from the institution. The team's questions focused on the lifespan of the pipes, water leak detection and general maintenance of the water distribution pipes. The team found that the average lifespan of water pipes is twenty five years and that the institutional water pipes were installed about forty two years ago. These pipes were lined with bitumen that has never been replaced and may have worn out over time. These two facts led the team to pay attention on water leak detection and examined the prospects of developing water leak detection devices for commercial use. The team's efforts were diagnostic and focused on improving the quality of local pipes through early detection and fixing of leaks. This team presented its findings in Learnshop 8.

Learnshops 9 and 10 were intended to post-test students on the TTCT metric variables of fluency, flexibility and originality and then wrap up the project. The post-learnshops TTCT results on fluency, flexibility and originality were then compared with those of the pre-learnshops intervention and were tested for statistical significance through the t-test where $\mathrm{N}=24$ (Table 3.1). 


\section{THE SCHOLARSHIP OF TEACHING AND LEARNING IN HIGHER EDUCATION}

\section{Learnshops 8 and 9: Evaluating creativity}

The findings in Table 3.1 indicate that two of the three metric variables that measured students' creativity show significant improvement on students' generation of a variety of ideas $(p=0,003)$ and the unusualness of the generated ideas $(p=0,001)$. The mean scores of all three metric variables of the TTCT increased when the pre- and post-test scores of students are compared, which indicates the general improvement of students' creativity performance post-intervention. The t-test also shows statistical significance between the TTCT metric variables, which indicates that students scores on fluency, flexibility and originality increased post-intervention although with varying degrees. The standard deviation increased post-intervention as the result of two students making no progress at all during the intervention. These findings provide solid evidence that learning conditions that were developed in the learnshops as underpinned by invitational pedagogy (safe conversations, guided problem solving, inquiry orientation) were effective in developing students' creativity.

TABLE 3.1 Mean, standard deviation, t-test and p-value of TTCT scores

\begin{tabular}{|l|c|c|c|c|c|c|}
\hline & \multicolumn{2}{c}{ PRE-TEST } & \multicolumn{2}{c}{ POST-TEST } \\
\hline Mean & $\begin{array}{c}\text { Standard } \\
\text { deviation }\end{array}$ & Mean & $\begin{array}{c}\text { Standard } \\
\text { Deviation }\end{array}$ & t-test & p-value \\
\hline Fluency & 47,83 & 8,65 & 58,25 & 20,32 & $-2,614$ & 0,016 \\
\hline Flexibility & 36,33 & 9,49 & 45,46 & 14,59 & $-3,291$ & 0,003 \\
\hline Originality & 24,08 & 7,57 & 33,71 & 12,18 & $-3,975$ & 0,001 \\
\hline
\end{tabular}

\section{ACKNOWLEDGEMENT}

The participation of Thabo Maloka and Malefane Lebusa as critical friends in this project is acknowledged and appreciated. Siyabonga bafethu!

\section{REFERENCES}

Altshuller G. 1984. Creativity as an exact science. New York: Gordon and Breach Science Publishing.

Baillie C \& Walker P. 1998. Fostering creative thinking in student engineers. European Journal of Engineering Education, 23(1):35-43.

Bakhtin MM \& Holquist M. 1981. The dialogic imagination: Four essays. Austin, TX: University of Texas Press.

Bowden J \& Marton F. 1998. The university of learning: Beyond quality and competence. London: Routledge.

Brew A. 2003. Teaching and research: New relationships and their implications for inquirybased teaching and learning in higher education. Higher Education Research \& Development, 22(1):3-18. 
Boyer EL. 1990. Scholarship reconsidered: Priorities of the professoriate. Stanford, CA: The Carnegie Foundation for the Advancement of Teaching.

Boyer EL. 1998. The Boyer Commission on Educating Undergraduates in the Research University, reinventing undergraduate education: A blueprint for America's research universities. Menlo Park, CA: Carnegie Foundation for the Advancement of Teaching.

Cahan D. 1985. The institutional revolution in German physics 1865-1914. Historical Studies in the Physical Sciences, 15:1-65.

Castells M, Muller J, Cloete N \& Badat S. 2001. Challenges of globalisation: South African debates with Manuel Castells. Pinelands, Cape Town: Maskew Miller Longman.

Chang P \& Hsiau S. 2002. Implementation of an innovative curriculum to cultivate technological creativity in engineering studies. Proceedings of the National Academy of Sciences (ROC), 12(2):64-72.

Cohen L, Manion L \& Morrison K. 2000. Research methods in education. London: Routledge.

Cropley H. 2000. Fostering creativity in engineering undergraduates. High Abilities Studies, $11(2): 207-219$.

Cunningham S. 2006. What price a creative economy? Platform Papers No. 9, July. Sydney: Currency House.

Csikszentmihalyi M. 2006. Foreword: Developing creativity. In: M Oliver, M Shaw \& J Wisdom (eds.). Developing creativity in higher education. Abingdon: Routledge. xviii-xx.

Dillon P. 2006. Creativity, integrativism and a pedagogy of connection. Thinking Skills and Creativity, 1 (2):69-83.

Edwards M, McGoldrick C \& Oliver M. 2006. Creativity and curricula in higher education: academics'perspectives. In: N Jackson, M Oliver, M Shaw \& J Wisdom (eds.). Developing creativity in higher education: An imaginative curriculum. Abingdon: Routledge. 59-73.

Florida R. 2002. The rise of the creative class. And how it's transforming work, leisure and everyday life. London: Basic Books.

Florida R \& Goodnight J. 2005. Managing for creativity. Harvard Business Review, 83(7):124-131.

Foss S. 1993. Beyond persuasion: A proposal for an invitational rhetoric. Prospects Heights, IL: Waveland.

Forrester V \& Hui A. 2007. Creativity in the Hong Kong classroom: What is the contextual practice? Thinking Skills and Creativity, 2:30-38.

Griffiths R. 2004. Knowledge production and the research-teaching nexus: The case of the built environment disciplines. Studies in Higher Education, 29(6):709-726.

Jackson N. 2008. Tackling the wicked problem of creativity in higher education. ARC Presentation at the ARC Centre for the Creative Industries and Innovation. International Conference, Brisbane.

Jackson N \& Shaw M. 2006. Subject perspectives on creativity. In: N Jackson (ed.). Developing creativity in higher education: An imaginative curriculum. London: Routledge. 89-108.

Kalantzis M \& Cope B. 2008. New learning: Elements of a science of education. Cambridge: Cambridge University Press. 


\section{THE SCHOLARSHIP OF TEACHING AND LEARNING IN HIGHER EDUCATION}

Korten DC. 1995. When corporations rule the world. West Hartford: Kumarian Press.

Martinsen O. 1995. Cognitive styles and experience in solving insight problems: replication and extension. Creativity Research Journal, 8:291-298.

Olesko K. 2005. The foundations of a canon: Kohlrausch's practical physics. In: D Kaiser (ed.). Pedagogy and the practice of science: Historical and contemporary perspectives. Cambridge, MA: MIT Press. 323-356.

Oliver M, Shah B, McGoldrick C \& Edwards M. 2006. In: N Jackson, M Oliver, M Shaw \& J Wisdom (eds.). Developing creativity in higher education: An imaginative curriculum. New York: Routledge.

Perry W. 1970. Forms of intellectual and ethical development in the college years. New York: Holt, Rinehart and Winston.

Peters T. 2003. Re-imagine: Business excellence in a disruptive age. New York: Penguin.

Pink D. 2005. A whole new mind. New York: Penguin.

Pitso T. 2011 . Fostering creativity in engineering undergraduates. Unpublished PhD thesis. Johannesburg: University of the Witwatersrand.

Polivinkin A. 1985. Laws of organization and evolution of technique. Volgograd: Volgograd Polytechnical Institute.

Polivinkin A. 1991. Theory of new technique design: laws of technical systems and their applications. Moscow: Informelektro.

Potter M \& Kustra E. 2011 . The relationship between scholarly teaching and SoTL: Models, distinctions and clarifications. International Journal for the Scholarship of Teaching and Learning, 5(1): 1-18.

Rantanen K \& Domb E. 2002. Simplified TRIZ: New problem-solving applications for engineers and manufacturing professionals. London: St. Lucie Press.

Runté R. 1995. Is teaching a profession? In: G Taylor \& R Runte (eds.). Thinking about teaching: An Introduction. Toronto, Canada: Harcourt Brace. 288-299.

Savransky S. 2000. Engineering of creativity. New York: CRC Press.

Sklobosvsky K \& Sharipov R. 1995. Theory, practice and application of inventive problems decision. Obninsk: Protva-Prin.

Suzuki D. 2009. Doing business in a new climate: A guide to measuring, offsetting greenhouse gas emissions. Vancouver, Canada: David Suzuki Foundation.

Tom A. 1997. The deliberative relationship: A frame for talking about faculty-student relationships. The Alberta Journal of Educational Research, 43(1):3-21.

Törnkvist S. 1998. Creativity: Can it be taught? The case of engineering education. European Journal of Engineering Education, 23(1):5-12.

Wilcoxson L, Manning M, Johnston N \& Gething K. 2011 . Enhancing the research-teaching nexus: Building teaching-based research from research-based teaching. International Journal of Teaching and Learning in Higher Education, 23(1):1-10. 